\title{
Fire and explosion analysis of filling station based on fuzzy mathematics and Bayesian network model
}

\author{
Kezhen Chen ${ }^{1}$, Jihong $\mathrm{Ye}^{2, b^{*}}$, Xiaofeng Zhang ${ }^{3}$ and Qingqing $\mathrm{Lv}^{4}$ \\ ${ }^{1}$ School of Naval Architecture and Maritime, Zhejiang Ocean University, ZhouShan, Zhejiang, China \\ ${ }^{2,3,4}$ School of Petrochemical Engineering and Environment, Zhejiang Ocean University, ZhouShan, Zhejiang, China
}

\begin{abstract}
In order to explore the basic events and risk occurrence probability of fire and explosion accidents in CNG (Compressed Natural Gas) filling station, a corresponding Bayesian network risk model was established based on the fault tree of filling station. The prior probability was modified by introducing fuzzy mathematics in the process of transforming the fault tree into Bayesian network, and the posterior probability of the basic events of CNG filling station fire and explosion accidents was analyzed and calculated by GeNIe software. Finally, through case analysis, it is found out that the most dangerous factors that lead to the greatest risk of fire and explosion accidents in a filling station are: personnel misoperation, management defects, etc. After verifying the model, it shows that paying attention to the polymorphism of the base events and determining the rationality of the logical relationship between the base events can calculate the more accurate probability distribution of the base events, and at the same time provide reasonable suggestions for the accident prevention of the gas filling station.
\end{abstract}

\section{Introduction}

With the shortage of oil resources in China and the increasingly serious air pollution in cities, natural gas energy has developed rapidly in recent years. The number of filling stations that provide fuel for natural gas vehicles and large $\mathrm{CNG}$ energy vehicles is also increasing day by day. The number of gas stations provided by natural gas vehicles and large CNG energy vehicles is also increasing. In addition, there are many oil and gas products stored in CNG gas filling stations, and the process is complicated, which is easy to cause fire and explosion accidents. Therefore, it is vital to find out the key basic events and risk probability of fire and explosion accidents at $\mathrm{CNG}$ filling stations, which has practical guiding significance for reducing the fire and explosion accidents at $\mathrm{CNG}$ filling stations. Yuan Changfeng [1] used fuzzy dynamic fault tree to analyze the contributing factors in the emergency process of oil and gas storage and transportation fire accidents, and introduced triangular fuzzy numbers to refine the occurrence probability of each factor. Fan Chen [2] takes Langfang CNG filling station as an example for comprehensive fuzzy evaluation, and uses AHP to determine the weight, but there is no connection among the sub-factors. Wang Chengtang [3] put forward a method to evaluate the collapse possibility of deep foundation pit based on polymorphic fuzzy Bayesian network, which broke through the limitations of traditional risk analysis of complex systems. In order to improve the accuracy of fire risk assessment, Mi Hongfu [4] used bow analysis method to establish potential fire accident scenarios, and introduced Bayesian network to predict and analyze fire probability. Studying from the reasoning mechanism, the shortcomings of the fault tree model can be effectively compensated by Bayesian network. In this paper, the fault tree analysis method is combined with Bayesian network method, aiming at the fire and explosion accident of gas station, and fuzzy mathematics is introduced in the process of transforming the fault tree into Bayesian network.

\section{Research methods}

\subsection{Fault tree analysis}

Fault Tree Analysis (FTA) is one of the important analysis methods in the discipline of system safety engineering. First, it selects the specific accident (top event) to be studied, deduces it layer by layer, and finds the basic cause of the accident (bottom event). In fact, the principle of fault tree analysis is similar to the thinking process of human brain in dealing with complex events. A top event is taken as the source of deliberation, and then a number of influencing factors are listed layer by layer according to pyramid. Through qualitative and quantitative analysis, the most influential risk factors and potential risk factors are solved. In this paper, the causes of fire and explosion accidents in CNG filling stations are studied from four aspects: "human, machine, environment and management", and an accident tree diagram is drawn for detailed analysis.

*Corresponding author: b510186089@qq.com 


\subsection{GeNle builds Bayesian network model}

Bayesian network is a graphical visualization network based on probabilistic reasoning. Since it was proposed by Pearl in 1988, it has been widely used in medical diagnosis, statistical decision-making, risk prediction and other fields. Any abstract problem is transformed into component variables, and the connection between components represents the probability dependence between attributes (data variables), which gradually extends from the root node to the non-root node, and finally forms a Directed Acyclic Graph.

GeNIe software is a theoretical decision-making model for building a graphical development environment. This software has been widely used in decision-making system laboratory and University of Pittsburgh, and a series of commercial applicationshave also been developed [5]. According to the principle of mapping relationship between fault tree and Bayesian network diagram, the fire and explosion fault tree of CNG filling station is transformed into Bayesian network by GeNIe software.

In the Bayesian probability graph model composed of nodes and arrowed line segments, nodes represent random variables, and directed line segments between nodes represent the causal relationship between two nodes [6]. The arrow points out from the parent node that the arrow points to the child node. Nodes without parent nodes have no other nodes as conditions, and their probability is called the prior probability of these variables [7].

To put it simply, suppose there are two events A and B. $\mathrm{P}(\mathrm{A})$ indicates the occurrence probability of event $\mathrm{A}, \mathrm{P}(\mathrm{B})$ indicates the occurrence probability of event $\mathrm{B}, \mathrm{P}(\mathrm{A} \mid \mathrm{B})$ indicates the occurrence probability of event $A$ when event $\mathrm{B}$ is known, and $\mathrm{P}(\mathrm{B} \mid \mathrm{A})$ represents that the occurrence probability of event $\mathrm{B}$ when event $\mathrm{A}$ is known [8]. Therefore, if $\mathrm{A}$ is a parent node and $\mathrm{B}$ is a child node, the probability of event $\mathrm{A}$ is $\mathrm{P}(\mathrm{A})$, and the probability of event $\mathrm{B}$ is $\mathrm{P}(\mathrm{B} \mid \mathrm{A})$, so the conditional probability value of event $\mathrm{B}$ is calculated as follows:

$$
\mathrm{P}(\mathrm{B} \mid \mathrm{A})=(\mathrm{P}(\mathrm{B}) \times \mathrm{P}(\mathrm{A} \mid \mathrm{B})) /(\mathrm{P}(\mathrm{A}))
$$

In the formula, $\mathrm{P}(\mathrm{B} \mid \mathrm{A})$ is the probability of event $\mathrm{b}$ after event a is known, and its value is related to event a, so it is called the posterior probability of $\mathrm{B}$. $\mathrm{P}(\mathrm{B})$ is the prior probability of event $\mathrm{B}$ (marginal probability), and $\mathrm{P}(\mathrm{A})$ is the prior probability of event $\mathrm{A}$ (marginal probability), which also represents the general distribution of the event in the natural state. Therefore, in this paper, the prior probability of each node is its natural distribution probability in the database.

\subsection{Introduction of fuzzy numbers}

Fuzzy mathematics, also known as fuzzy mathematics, is a mathematical theory and method to study and deal with fuzzy phenomena. It is usually used to describe a series of thinking processes of judgment, reasoning, evaluation, decision-making and control, and has been widely used in the environment, chemical industry, medical, agriculture and forestry, remote sensing, control and many other fields. $\widetilde{A}$ mapping from $\mathrm{E}$ to the unit interval $[0,1]$ on the domain $\mathrm{E}, \widetilde{\mathrm{A}}: \mathrm{E} \rightarrow[0,1]$, is called a fuzzy subset of E.Suppose $\widetilde{A}$ is a fuzzy subset on $E, \quad \forall \lambda \in[0,1]$, so $A=\{x \mid \widetilde{A} \geq \lambda, x \in \widetilde{A}\}$ is called the $\lambda$-cut sets of $\widetilde{A}$. In particular, $\widetilde{\mathrm{u}}=(\underline{\mathrm{u}}, \mathrm{u}, \overline{\mathrm{u}})$ is called triangular fuzzy number, if its membership function $\widetilde{\mathrm{u}}(\mathrm{x}): \mathrm{R}=[0,1]$ is:

$$
\widetilde{u}(x)=\left\{\begin{array}{l}
\frac{\mathrm{x}-\underline{\mathrm{u}}}{\mathrm{u}-\underline{\mathrm{u}}}, \mathrm{x} \in(\underline{\mathrm{u}}, \mathrm{u}) \\
\frac{\mathrm{x}-\overline{\mathrm{u}}}{\mathrm{x}-\overline{\mathrm{u}}}, \mathrm{x} \in(\mathrm{u}, \overline{\mathrm{u}}) \\
1, \mathrm{x}=\mathrm{u} \\
0, \mathrm{x} \in(-\infty, \underline{\mathrm{u}}) \cup(\overline{\mathrm{u}},+\infty)
\end{array}\right.
$$

The element $\mathrm{X} \in \mathrm{R}$ of triangular fuzzy number is a real number, and the membership function $\widetilde{\mathrm{u}}(\mathrm{x})$ is explained as the degree to which the element $\mathrm{x}$ belongs to the fuzzy set $\widetilde{\mathrm{u}} \cdot \underline{\mathrm{u}}, \overline{\mathrm{u}}$ represent the lower bound function and the upper bound function of triangular fuzzy numbers, respectively, and the difference represents the degree of ambiguity.

Fuzzy numbers also have corresponding arithmetic operation rules. In this paper, a simple calculation method of addition, subtraction, multiplication and division of fuzzy numbers is adopted. The $\lambda$-cut sets of fuzzy number $\widetilde{\mathrm{A}}$ can also be expressed as $\mathrm{A}=[\underline{\mathrm{u}}(\mathrm{x}), \overline{\mathrm{u}}(\mathrm{x})]$. Especially, when fuzzy number $\widetilde{A}$ is triangular fuzzy number $(1, m, n)$, then $\mathrm{A}=[1+(\mathrm{m}-1) \lambda, \mathrm{n}-(\mathrm{n}-\mathrm{m}) \lambda]$.

\subsection{Fuzziness of expert language}

In order to analyze the probability of fire and explosion accidents in CNG filling station accurately by using fuzzy number, the opinions of five experts are listened to and synthesized in this paper. When experts assess the probability of fire and explosion accidents, they use "basically impossible", "likely" and "very likely" to evaluate, and the expert language needs to be fuzzified, as shown in Table 1.

The $\lambda$-cut set of fuzzy numbers corresponding to expert languages can be expressed as:

$$
\begin{aligned}
& \mathrm{A}_{1}=[0.1 \lambda,-0.2 \lambda+0.3] ; \\
& \mathrm{A}_{2}=[0.2 \lambda+0.1,-0.2 \lambda+0.5] ; \\
& \mathrm{A}_{3}=[0.2 \lambda+0.3,-0.2 \lambda+0.7] ; \\
& \mathrm{A}_{4}=[0.2 \lambda+0.5,-0.2 \lambda+0.9] ; \\
& \mathrm{A}_{5}=[0.2 \lambda+0.7,-0.1 \lambda+1.0] .
\end{aligned}
$$

Table 1. Expert language and corresponding fuzzy numbers.

\begin{tabular}{|c|c|c|c|}
\hline & Expert Language & $\begin{array}{c}\text { Semantic } \\
\text { Shift } \\
\text { value }\end{array}$ & Fuzzy Number \\
\hline 1 & $\begin{array}{c}\text { Accidents are } \\
\text { extremely } \\
\text { unlikely to } \\
\text { happen }\end{array}$ & VL & $\tilde{\mathrm{A}}_{1}=(0.0,0.1,0.3)$ \\
\hline
\end{tabular}




\begin{tabular}{|c|c|c|c|}
\hline 2 & $\begin{array}{c}\text { Accidents are } \\
\text { basically } \\
\text { impossible to } \\
\text { happen }\end{array}$ & $\mathrm{L}$ & $\widetilde{\mathrm{A}}_{2}=(0.1,0.3,0.5)$ \\
\hline 3 & $\begin{array}{c}\text { Accidents are } \\
\text { likely to happen }\end{array}$ & $\mathrm{M}$ & $\widetilde{\mathrm{A}}_{3}=(0.3,0.5,0.7)$ \\
\hline 4 & $\begin{array}{c}\text { Accidents are } \\
\text { very likely to } \\
\text { happen }\end{array}$ & $\mathrm{H}$ & $\widetilde{\mathrm{A}}_{+}=(0.5,0.7,0.9)$ \\
\hline 5 & $\begin{array}{c}\text { Accidents are } \\
\text { most likely to } \\
\text { happen }\end{array}$ & $\mathrm{VH}$ & $\widetilde{\mathrm{A}}_{s}=(0.7,0.9,1.0)$ \\
\hline
\end{tabular}

\subsection{Defuzzification and prior probability}

In the implementation of fuzzy control, in a number of control laws on the calculation of reasoning, the occurrence probability of nodes in the model that is defuzzification. Lion and Wang proposed a convenient integral solution in defuzzification, the formula is as follows:

$$
I=\eta \mu_{R}(A)+(1-\eta) \mu_{L}(A)
$$

Where: $I$ is the value of fuzziness; $\eta$ is the optimisticpessimism coefficient, if $\eta>0.5$, indicating that experts are pessimistic, if $\eta<0.5$, it means that experts are optimistic, $\eta=0.5$, which means experts are neutral; $\mu_{R}$ (A) represents the right expected value of fuzzy number A; $\mu_{\mathrm{L}}(\mathrm{A})$ represents the left expected value of fuzzy number $\mathrm{A}$.

For triangular fuzzy numbers, $\mu_{\mathrm{R}}(\mathrm{A})$ and $\mu_{\mathrm{L}}$ (A) are represented by the $\lambda$-cut sets as follows :

$$
\begin{aligned}
& \mu_{\mathrm{L}}(\mathrm{A})=\frac{1}{2}\left[\sum_{\lambda=0.1}^{1} \mathrm{n}^{\lambda} \Delta \lambda+\sum_{\lambda=0}^{0.9} \mathrm{n}^{\lambda} \Delta \lambda\right] \\
& \mu_{\mathrm{R}}(\mathrm{A})=\frac{1}{2}\left[\sum_{\lambda=0.1}^{1} \mathrm{~m}^{\lambda} \Delta \lambda+\sum_{\lambda=0}^{0.9} \mathrm{~m}^{\lambda} \Delta \lambda\right]
\end{aligned}
$$

Where: $\lambda=0,0.1, \cdots, 1 ; \Delta \lambda=0.1 ; \mathrm{m}^{2} 、 \mathrm{n}^{2}$ are the upper and lower bounds of the $\lambda$-cut set of the fuzzy number A.

The defuzzified values can be used as the prior probability of the underlying event. The posterior probability is calculated according to the prior probability and the Bayesian network.

\section{Case study}

\subsection{Fault tree model of fire and explosion in CNG filling station}

Taking a CNG filling station in Zhoushan, Zhejiang Province as an example, the accident assessment is carried out from the four main aspects of "human", "machine", "environment" and "management", and the basic steps of fault tree analysis are followed to establish the fire and explosion fault tree model of CNG filling station. The fire and explosion fault tree of CNG filling station is shown in
Figure 1, and the event code of fault tree is shown in Table 2.

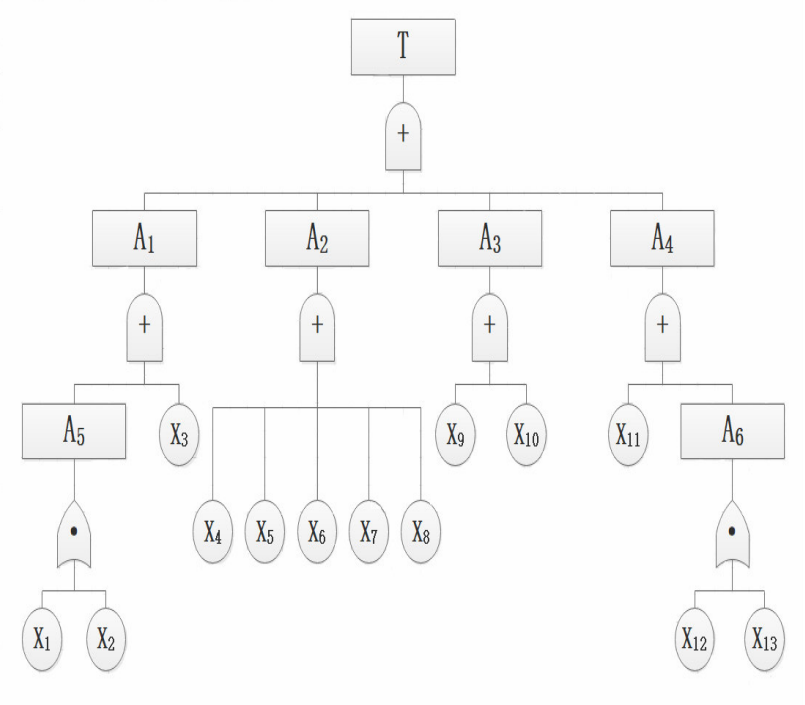

Figure 1. Filling station fire and explosion fault tree.

Table 2. Fault tree code and corresponding events.

\begin{tabular}{|c|c|c|c|}
\hline Code & Event & Code & Event \\
\hline $\mathrm{T}$ & $\begin{array}{c}\text { Filling station fire } \\
\text { and explosion }\end{array}$ & $\mathrm{X}_{5}$ & Design defect \\
\hline $\mathrm{A}_{1}$ & Human factor & $\mathrm{X}_{6}$ & $\begin{array}{c}\text { Construction } \\
\text { deficiency }\end{array}$ \\
\hline $\mathrm{A}_{2}$ & Machine factor & $\mathrm{X}_{7}$ & Equipment trouble \\
\hline $\mathrm{A}_{3}$ & $\begin{array}{c}\text { Environmental } \\
\text { factor }\end{array}$ & $\mathrm{X}_{8}$ & $\begin{array}{c}\text { Poor material or } \\
\text { aging of } \\
\text { equipment }\end{array}$ \\
\hline $\mathrm{A}_{4}$ & $\begin{array}{c}\text { Management } \\
\text { factor }\end{array}$ & $\mathrm{X}_{9}$ & $\begin{array}{c}\text { Natural disaster } \\
\mathrm{X}_{1}\end{array}$ \\
$\begin{array}{c}\text { Personnel } \\
\text { misoperation }\end{array}$ & $\mathrm{X}_{10}$ & $\begin{array}{c}\text { Peripheral high- } \\
\text { risk activities }\end{array}$ \\
\hline $\mathrm{X}_{2}$ & $\begin{array}{c}\text { Low quality of } \\
\text { staff }\end{array}$ & $\mathrm{X}_{11}$ & $\begin{array}{c}\text { Network system } \\
\text { fault }\end{array}$ \\
\hline $\mathrm{X}_{3}$ & $\begin{array}{c}\text { Man-made } \\
\text { destruction }\end{array}$ & $\mathrm{X}_{12}$ & $\begin{array}{c}\text { Management } \\
\text { defects }\end{array}$ \\
\hline $\mathrm{X}_{4}$ & $\begin{array}{c}\text { Gas quality } \\
\mathrm{X}_{13}\end{array}$ & $\begin{array}{c}\text { Lack of protective } \\
\text { measures }\end{array}$ \\
\hline
\end{tabular}

\subsection{Transform fault tree into Bayesian network}

Bayesian network expresses the conditional independence and dependence among nodes. We can intuitively get the conditional independence and dependence among attributes from Bayesian network. Another advantage of Bayesian network is that it can represent the joint probability distribution of events. According to the network structure of Bayesian network, we can deduce the probability of each basic event.

Set up the network in Genie software, as shown in Figure 2. In order to make the display effect more intuitive, set the display type to bar chart. The posterior probability 
of each basic event can be calculated by adding the prior probability value after fuzzy aggregation and the value in the conditional probability table to Genie software, as shown in Figure 2, and the calculation results are shown in Table 4.

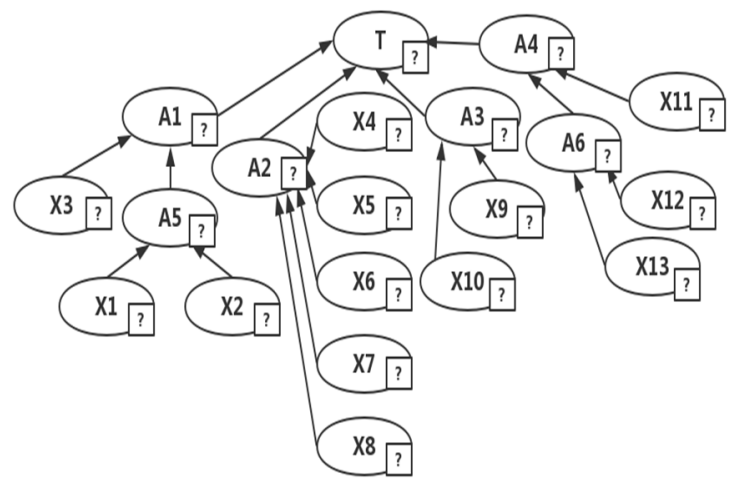

Figure 2. Bayesian network diagram of filling station fire and explosion.

\subsection{Defuzzification}

In this paper, five experts are selected to evaluate and score the possibility of the consequences of fire and explosion in gas filling stations by using fuzzy language, and the evaluation results are shown in Table 3.

Table 3. Expert scoring table.

\begin{tabular}{|c|c|c|c|c|c|}
\hline $\mathrm{X}_{1}$ & $\mathrm{H}$ & $\mathrm{M}$ & $\mathrm{M}$ & $\mathrm{M}$ & $\mathrm{H}$ \\
\hline $\mathrm{X}_{2}$ & $\mathrm{~L}$ & $\mathrm{VL}$ & $\mathrm{VL}$ & $\mathrm{M}$ & $\mathrm{VL}$ \\
\hline $\mathrm{X}_{3}$ & $\mathrm{VL}$ & $\mathrm{M}$ & $\mathrm{M}$ & $\mathrm{VL}$ & $\mathrm{H}$ \\
\hline $\mathrm{X}_{4}$ & $\mathrm{VL}$ & $\mathrm{L}$ & $\mathrm{L}$ & $\mathrm{VL}$ & $\mathrm{L}$ \\
\hline $\mathrm{X}_{5}$ & $\mathrm{VL}$ & $\mathrm{VL}$ & $\mathrm{VL}$ & $\mathrm{VL}$ & $\mathrm{VL}$ \\
\hline $\mathrm{X}_{6}$ & $\mathrm{VL}$ & $\mathrm{VL}$ & $\mathrm{VL}$ & $\mathrm{VL}$ & $\mathrm{VL}$ \\
\hline $\mathrm{X}_{7}$ & $\mathrm{H}$ & $\mathrm{M}$ & $\mathrm{M}$ & $\mathrm{M}$ & $\mathrm{L}$ \\
\hline $\mathrm{X}_{8}$ & $\mathrm{H}$ & $\mathrm{M}$ & $\mathrm{H}$ & $\mathrm{L}$ & $\mathrm{H}$ \\
\hline $\mathrm{X}_{9}$ & $\mathrm{VL}$ & $\mathrm{VL}$ & $\mathrm{VL}$ & $\mathrm{VL}$ & $\mathrm{VL}$ \\
\hline $\mathrm{X}_{10}$ & $\mathrm{M}$ & $\mathrm{H}$ & $\mathrm{H}$ & $\mathrm{L}$ & $\mathrm{VL}$ \\
\hline $\mathrm{X}_{11}$ & $\mathrm{~L}$ & $\mathrm{~L}$ & $\mathrm{~L}$ & $\mathrm{~L}$ & $\mathrm{VL}$ \\
\hline $\mathrm{X}_{12}$ & $\mathrm{~L}$ & $\mathrm{VL}$ & $\mathrm{VL}$ & $\mathrm{VL}$ & $\mathrm{L}$ \\
\hline $\mathrm{X}_{13}$ & $\mathrm{~L}$ & $\mathrm{~L}$ & $\mathrm{M}$ & $\mathrm{M}$ & $\mathrm{L}$ \\
\hline
\end{tabular}

The specific steps of the defuzzification process are as follows:

(1) According to each expert's evaluation semantic value for any event to be evaluated, and according to the corresponding relationship between semantic value and triangular fuzzy number in Table 1 , it is converted into corresponding standard fuzzy number.

(2) Judge the weight of each expert. The weighted average method is used to determine the weight of each expert according to the qualification, professional title, working time limit and professional counterpart degree of each expert. The specific weight values are Expert 1: 0.306, Expert 2: 0.250, Expert 3: 0.139, Expert 4: 0.111, Expert 5: 0.194.

(3) According to formula (3), (4) and table 2 and table 3 , the prior probability is obtained by fuzzy aggregation.

(4) The calculation results are listed in Table 4. Using Genie software, the posterior probability of each basic event can be calculated by adding the calculated prior probability value and conditional probability to Genie software (the conditional probability value is based on the probability statistics of fire and explosion accidents in recent five years).

Table 4. Probability of accident causation.

\begin{tabular}{|c|c|c|c|}
\hline \multirow{2}{*}{ Code } & \multirow{2}{*}{ Basic event } & \multicolumn{2}{|c|}{ Probability of occurrence } \\
\hline & & $\begin{array}{c}\text { Prior } \\
\text { probability }\end{array}$ & $\begin{array}{l}\text { Posterior } \\
\text { probability }\end{array}$ \\
\hline $\mathrm{X}_{1}$ & $\begin{array}{c}\text { Personnel } \\
\text { misoperation }\end{array}$ & 0.6000 & 0.3214 \\
\hline $\mathrm{X}_{2}$ & $\begin{array}{l}\text { Low quality of } \\
\text { staff }\end{array}$ & 0.2056 & 0.0944 \\
\hline $\mathrm{X}_{3}$ & $\begin{array}{l}\text { Man-made } \\
\text { destruction }\end{array}$ & 0.3720 & 0.0142 \\
\hline $\mathrm{X}_{4}$ & Gas quality & 0.2166 & 0.0331 \\
\hline $\mathrm{X}_{5}$ & Design defect & 0.1000 & 0.0191 \\
\hline $\mathrm{X}_{6}$ & $\begin{array}{c}\text { Construction } \\
\text { deficiency }\end{array}$ & 0.1000 & 0.0153 \\
\hline $\mathrm{X}_{7}$ & Equipment trouble & 0.5224 & 0.0799 \\
\hline $\mathrm{X}_{8}$ & $\begin{array}{l}\text { Poor material or } \\
\text { aging of } \\
\text { equipment }\end{array}$ & 0.6056 & 0.1158 \\
\hline $\mathrm{X}_{9}$ & Natural disaster & 0.1000 & 0.0038 \\
\hline $\mathrm{X}_{10}$ & $\begin{array}{l}\text { Peripheral high- } \\
\text { risk activities }\end{array}$ & 0.4780 & 0.0549 \\
\hline $\mathrm{X}_{11}$ & $\begin{array}{l}\text { Network system } \\
\text { fault }\end{array}$ & 0.2612 & 0.0050 \\
\hline $\mathrm{X}_{12}$ & $\begin{array}{l}\text { Management } \\
\text { defects }\end{array}$ & 0.2000 & 0.1224 \\
\hline $\mathrm{X}_{13}$ & $\begin{array}{c}\text { Lack of protective } \\
\text { measures }\end{array}$ & 0.3500 & 0.1205 \\
\hline
\end{tabular}




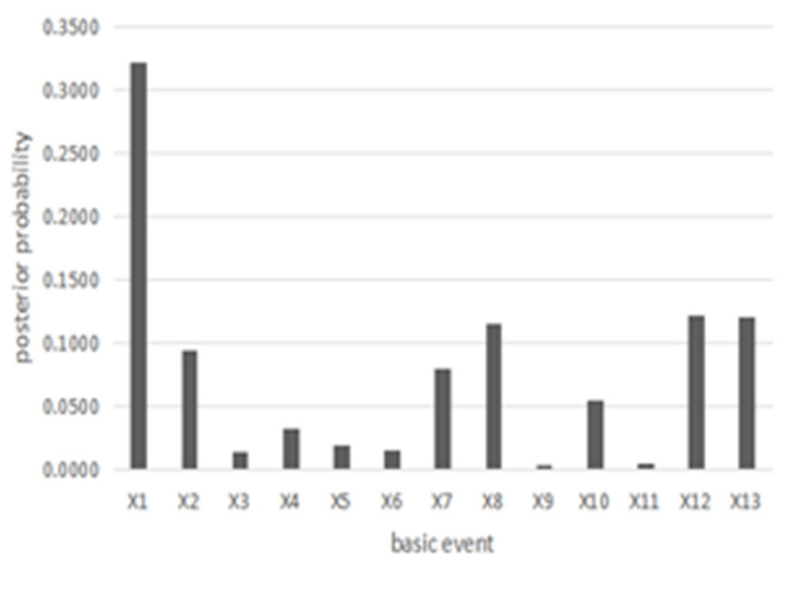

Figure 3. Basic event posterior probability histogram.

\subsection{Sensitivity analysis}

In the fault tree, the relationship between system failure and component failure is expressed by three importance degrees, which reflect the importance of components on the system from different angles [9]. The physical meaning of probability importance is the probability of system failure when and only if element $X$ fails. It reflects the degree of system change caused by the change of a component state. It provides the necessary intermediate characteristic quantity for the calculation of structural importance and critical importance. Structural importance is the result of probability importance under a special condition, which is mainly used for reliability allocation. The critical importance reflects the change rate of system failure probability caused by the change rate of failure probability of a certain element. It is mainly used for the design of system reliability parameters and the arrangement diagnosis check sequence table [10].

In the fault tree, it is necessary to solve all the minimum cut sets, and then use the inclusion exclusion theorem for accurate calculation, or use mutually exclusive approximation or independent approximation for approximate calculation [11]. In Bayesian networks, the joint probability distribution can be used to directly calculate the failure probability of system nodeswithout solving cut sets [12]. Therefore, if the probability of occurrence of each parent node of Bayesian network is increased to $100 \%$, then the risk probability of each child node will also change. This paper analyzes A2-(X4, X5, $\mathrm{X} 6, \mathrm{X} 7, \mathrm{X} 8)$ to illustrate the advantages and characteristics of Bayesian network using bidirectional reasoning algorithm to identify weak links in the system.

The sensitivity analysis results of each parent node are obtained by comparing the changes of the corresponding sub node probabilities. Table 5 shows the sensitivity analysis results of each risk element.

Table 5. Sensitivity analysis results.

\begin{tabular}{|c|c|c|c|c|c|}
\hline Element & $\mathrm{X}_{4}$ & $\mathrm{X}_{5}$ & $\mathrm{X}_{6}$ & $\mathrm{X}_{7}$ & $\mathrm{X}_{8}$ \\
\hline $\begin{array}{c}\text { Probability } \\
\text { of } \\
\text { occurrence }\end{array}$ & $\begin{array}{c}12.5 \\
9 \%\end{array}$ & $\begin{array}{c}7.26 \\
\%\end{array}$ & $\begin{array}{c}5.81 \\
\%\end{array}$ & $\begin{array}{c}30.3 \\
5 \%\end{array}$ & $\begin{array}{c}43.9 \\
9 \%\end{array}$ \\
\hline Sensitivity & $8 \%$ & $5 \%$ & $5 \%$ & $16 \%$ & $22 \%$ \\
\hline
\end{tabular}

Using Genie software to analyze the sensitivity of fire and explosion Bayesian network in gas station. Here, we mainly analyze the sensitivity of base events, and we can get some high sensitivity of some base events, such as X1, $\mathrm{X} 8, \mathrm{X} 12$.The higher the sensitivity, the more sensitive the risk factors are to the external environment, which is also in line with the actual situation of $\mathrm{CNG}$ filling station.

\section{Conclusion}

The Bayesian network analysis model based on fault tree overcomes the limitation of fault tree analysis method. The polymorphism of event state and the uncertainty of logical relationship which are difficult to describe in fault tree analysis can be realized by changing the corresponding conditional probability table in Bayesian network model.

By using Genie software, the posterior probability of basic events can be obtained. The modified Bayesian network model is more practical and improves the accuracy of quantitative analysis of gas station safety failure. According to the posterior probability analysis example, the high sensitivity and high risk factors of $\mathrm{CNG}$ filling station are mainly the personnel misoperation and management defects.

According to Bayesian network analysis, the causes of fire and explosion accidents in gas stations are common dangerous behaviors and dangerous elements. Therefore, in order to improve the safety of gas stations in actual production, we not only need to find out the dangerous reasons, but also need to strengthen the management procedures and standardize the behavior of personnel.

\section{References}

1. C. Yuan, Y. Zhang, Y. Hu, T. Zuo, J. Wang, S. Fan, Journal of Dalian Maritime University 47, 92100(2021)

2. C. Fan, Master's thesis, (2016)

3. C. Wang, H Wang, W. Qin, G. Zhong,W. Chen, Rock and Soil Mechanics 41, 1670-1679+1689(2019)

4. H. Mi, X. Zhang, W. Yang, W. Wang, Y. Liu, Y. Jiao, China Safety Science Journal 31, 165-172(2021)

5. E. Zhang,Master's thesis, (2015)

6. L. Fan, Z. Zhang, J. Yi, Operations Research and Management Science 28, 107-115(2019)

7. C. Xing, Principles and applications of artificial intelligence, 25 (2005)

8. G. Mao, Summary of probability theory and mathematical statistics methods and skills, 43(2009)

9. X. Yi. W. Qian, L. Xie, Acta Aeronautica et Astronautica Sinica, 1482-1489(2008)

10. L. Huo, Y. Zhu, Z. Zhang, L. Chen, Transactions of China Electrotechnical Society, 113-118(2004)

11. F. Zhang, S. Huang, Q. Guo, H. Liu, D. Dong, Urban Mass Transit 21, 52-56(2018)

12. Z. Zhou, D. Dong, J. Zhou, Systems EngineeringTheory \& Practice, 95-100(2006) 